\title{
青藏高原几种典型高山植物的光合特性比较
}

\author{
师生波 李惠梅 王学英 岳向国 徐文华 陈桂琛 \\ (中国科学院西北高原生物研究所, 西宁 810001)
}

\begin{abstract}
摘 要 选用西宁地区人工栽培的高山植物唐古特大黄( Rheum tanguticum)、山莨宕( Anisodus tanguticus) 和麻花艽 (Gentiana straminea), 比较了 3 种高山植物之间光合作用的光响应和 $\mathrm{CO}_{2}$ 响应特性, 叶片光合色素以及 UV-B 吸收物 质的差异; 并以低海拔植物菘蓝 (Isatis indigotica) 为对比, 分析了高山植物与低海拔植物的差异。结果表明: 与低海 拔植物蓊蓝相比, 3 种高山植物光合作用的表观量子效率 $(A Q Y)$ 都偏低; 唐古特大黄叶片的 $A Q Y$ 、羧化效率 $(C E)$ 和 光呼吸速率 $\left(R_{p}\right)$ 都很低, 净光合速率 $\left(P_{n}\right)$ 的光响应曲线在全日照光辐射范围内并没有达到完全饱和, 这与单位面 积叶片具有较高的光合色素以及 UV-B 吸收物质有关; 麻花艽植物与唐古特大黄一样, 具有较高的 UV-B 吸收物质 和光合色素含量, 但其 $R_{p}$ 较高, 加之 $P_{n}$ 受气孔限制较为明显, 故其光合作用的饱和光强很低, $P_{n}$ 相对于其它 3 种 植物也较低; 山莨宕与低海拔植物菘蓝的光合特性很相似, 都具有较高的 $A Q Y$ 和 $C E$ 。这些结果表明, 3 种高山植物 的光合特性有较大差异, 但并没有一致的相对于低海拔植物的共性。 4 种植物 $P_{n}$ 的胞间 $\mathrm{CO}_{2}$ 浓度 $\left(C_{i}\right)$ 响应曲线在 $\mathrm{CO}_{2}$ 饱和点以后都表现为无机磷 $\left(\mathrm{P}_{\mathrm{i}}\right)$ 再生限制, 其 $R_{p}$ 的变化与 $\mathrm{CO}_{2}$ 饱和点以后的最大 $P_{n}$ 的变化基本一致。
\end{abstract}

关键词 青藏高原 高山植物 药用植物 光合特性

\section{COMPARATIVE STUDIES OF PHOTOSYNTHETIC CHARACTERISTICS IN TYPICAL ALPINE PLANTS OF THE QINGHAI-TIBET PLATEAU}

\author{
SHI Sheng-Bo LI Hui-Mei WANG Xue-Ying YUE Xiang-Guo XU Wen-Hua and CHEN Gui-Chen \\ ( Northwest Plateau Institute of Biology, Chinese Academy of Sciences, Xining 810001, China)
}

\begin{abstract}
The photosynthetic characteristics of three medicinal alpine plants, Rheum tanguticum, Anisodus tanguticus and Gentiana straminea, were studied and compared to a low land species, Isatis indigotica. The response of net photosynthesis rate $\left(P_{n}\right)$ to intercellular $\mathrm{CO}_{2}$ concentrations $\left(C_{i}\right)$ and photon flux density $(P F D)$ was determined using a LI-6400 photosynthesis system. The photosynthetic pigments and UV-B-absorbing compounds also were determined in the four species in order to evaluate differences in their photosynthetic characteristics. The results indicated that the three alpine plants had relatively low photosynthetic quantum yields $(A Q Y)$ as compared to the low land species of $I$. indigotica, and $A Q Y$, carboxylation efficiency ( $C E$ ) and photorespiratory rate $\left(R_{p}\right)$ were the lowest in $R$. tanguticum. However, $P_{n}$ did not respond strongly to changes in PFD, which may be due to the high concentration of photosynthetic pigments and UV-Babsorbing compounds in the leaves. Similar to $R$. tanguticum, the alpine plant $G$. straminea also had higher contents of UV-B-absorbing compounds, chlorophyll and carotenoids, but its $R_{p}$ was higher and $P_{n}$ was limited by stomatal conductance in response to $P F D$ and $P_{n}$ was lower. The photosynthetic characteristics of the alpine species, A. tanguticus, was similar to the low land species, I. indigotica, both of which had a high AQY and $C E$. These results indicated that although there were some differences among the three alpine species, no corresponding characteristics appeared in photosynthetic advancements. The response of $P_{n}$ to $C_{i}$ exhibited $\mathrm{Pi}$ regeneration limitations after reaching full $\mathrm{CO}_{2}$ saturation. The changes of $R_{p}$ in the four species were similar to that of maximum $P_{n}$ in photosynthetic $C_{i}$ response.
\end{abstract}

Key words Qinghai-Tibet plateau, Alpine plant, Medicinal plant, Photosynthetic characteristics

高山地区的生存环境相对恶劣, 高山植物在长 期的自然选择和适应过程中, 不断与环境相互协调,
形成了一系列对严酷自然条件的适应机制。这已经 引起国内外学者的普遍关注 (卢存福等, 1995, 2000; 
吴学明, 1997; Goldstein et al., 1999)。早在 1991 年 Rawat 和 Purohit (1991) 就通过移栽实验发现, 4 种原 产地在高海拔 (3600 m) 的高山植物移至低海拔 $(550 \mathrm{~m})$ 后, 植物叶片的 $\mathrm{CO}_{2}$ 同化速率和水蒸汽交换 速率对光强和温度的响应与原产地的测定结果相比 较, 具有种的特异性 (Species specific), 说明生长海拔 的改变并不是影响植物气体代谢过程的唯一因素。

高山地区的显著特点之一是随海拔升高气温降 低, 日温差变大。通常认为高山植物能成功地适应 高山逆境的关键是发育和代谢能够在低温和较大日 温差下维持正常功能 (Larcher, 1980)。Goldstein 等 (1999) 以生长在夏威夷火山地区的高山巨大莲座状 植物 Argyroxiphium sandwicense 为材料, 研究了田间 和实验室生长条件下高山植物光合作用对不同生长 温度的响应, 以及对 $-15^{\circ} \mathrm{C}$ 到 $60^{\circ} \mathrm{C}$ 温度变化的抗性 差异。表明生长在不同昼夜温差下的高山植物具有 几乎相同的最大光合速率和光合适温, 但低温生长 环境中的高山植物具有较高的暗呼吸速率。

然而, 不同于热带环境中很小季节变化的温度 塑造, 青藏高原的高山植物, 由于长期受高海拔环境 中高寒低温、强辐射和低气压等极端胁迫环境的影 响, 在形态解剖和生理功能等方面具有某些特殊的 适应方式(吴学明, 1997; 卢存福等, 2000)。近 10 年 来, 我们采用典型高山植物研究了光合作用气体代 谢过程对环境因子的响应 (Ben et al. , 1992; 贲桂英 等, 1993; 卢存福等, 1995, 2000; 张树源等, 1995; 师生 波等, 2001), 但非离体状况下, 尤其是自然生长环境 中植物光合作用的限制因素是什么? 它们与低海拔 植物有无差异？我们还缺乏具体的实验证据。

本文以人工栽培的青藏高原典型高山药用植物 唐古特大黄 ( Rheum tanguticum)、山莨宕 (Anisodus tanguticus) 和麻花艽 (Gentiana straminea) 为材料, 并 以广泛栽培的低海拔植物菘蓝 (Isatis indigotica) 为 对比, 比较研究了它们的光合特性, 探讨了长期生长 在青藏高原地区的高山植物的光合作用对高原极端 环境的适应方式, 并为人工栽培提出了合理建议。

\section{1 材料和方法}

\section{1 实验样地}

实验样地设在位于青海省西宁市的中国科学院 西北高原生物研究所和距离研究所约 $5 \mathrm{~km}$ 的实验

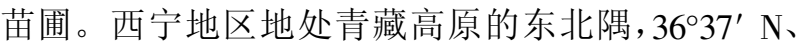
$101^{\circ} 46^{\prime} \mathrm{E}$; 海拔 $2300 \mathrm{~m}$ 。属高原大陆性半干旱气 候。气压低, 太阳辐射强烈, 年总辐射量达 588
$\mathrm{kJ} \cdot \mathrm{cm}^{-2}$ 。夏季暖湿, 东南季风时间较长, 年平均温度 为 $6.1{ }^{\circ} \mathrm{C}$, 年平均降雨量为 $371.2 \mathrm{~mm}$ 。

唐古特大黄、山莨宕和菘蓝种植于中国科学院 西北高原生物研究所院内实验苗戋, 为两年生的实 生苗。麻花艽种植在距离研究所约 $5 \mathrm{~km}$ 的实验苗 固,也为两年生的实生苗。

\section{2 植物材料}

唐古特大黄: 属苶科多年生高大草本, 是重要的 中药材, 为常用泻下药。分布于青海省的海北、果洛 和玉树等地区, 以及西藏东部和四川西部, 生长于海 拔 $1700 \sim 3900 \mathrm{~m}$ 的山地林缘、灌从和草坡等处。

山莨宕: 茄科多年生宿根草本。山莨宕除中药 用做麻醉镇静以及外用治疗溃疡恶疮及红肿疔毒 外, 也是提取莨宕烷类生物碱的重要资源植物。分 布于青海、西藏以及四川和甘肃等地区, 生长于海拔 $2200 \sim 4200 \mathrm{~m}$ 的山坡、沟边、路旁、田埂及畜圈等 处。

菘蓝: 十字花科菘蓝属植物, 二年生草本。根称 为板蓝根, 叶为大青叶。其根、叶均可入药, 具有清 热解毒、凉血等功效。主产于安徽、河北、河南和陕 西等省, 别名大青根、蓝靛等。

麻花艽: 龙胆科多年生草本。麻花艽在传统藏 医里用于治疗关节痛、肺病发烧和黄疸等症。分布 于青海、西藏以及四川和甘肃等地区, 生于海拔 $2500 \sim 4700 \mathrm{~m}$ 的山坡、河滩、草地和灌从中。

\section{3 测定方法及数据处理}

\subsection{1 叶片光合速率的测定}

从每一栽培的植物种群中, 各选接受自然太阳 辐射相近的叶片若干。用便携式光合气体分析系统 (LI-6400, Li-Cor Inc., Lincoln NE, USA)进行气体交 换测定。测定时间为 5 月至 6 月上旬, 此时所有植 物均处于营养生长早期。测定时叶室环境因子的控 制除注明外均为叶片温度为 $20{ }^{\circ} \mathrm{C}$, 气源 $\mathrm{CO}_{2}$ 浓度为 $350 \mu \mathrm{mol} \mathrm{CO} \mathrm{CO}_{2} \cdot \mathrm{mol}^{-1}$, 光量子通量密度 $(P F D)$ 为 1000 $\mu \mathrm{mol}$ photons $\cdot \mathrm{m}^{-2} \cdot \mathrm{s}^{-1}$ 。实验选在全晴天进行, 并进 行 $5 \sim 6$ 次重复。

叶片表观量子效率 $(A Q Y)$ 的计算以光响应曲线 中 $0 \sim 200 \mu \mathrm{mol}$ photons $\cdot \mathrm{m}^{-2} \cdot \mathrm{s}^{-1}$ 之间的净光合速率 $\left(P_{n}\right)$ 对 $P F D$ 做直线回归, 得回归方程:

\section{$P_{n}=R_{d}+A Q Y \times P F D$}

当 $P_{n}=0$ 时, $P F D$ 即为光合作用的光补偿点 $\Phi_{i}$ 。这里 $R_{d}$ 为暗呼吸速率。

叶片羧化效率的计算以 $P_{n}$ 对胞间 $\mathrm{CO}_{2}$ 浓度 
$\left(C_{i}\right)$ 曲线中 $0 \sim 200 \mu \mathrm{mol} \mathrm{CO}_{2} \cdot \mathrm{mol}^{-1}$ 的点做直线回 归, 得回归方程:

$$
P_{n}=R_{p}+C E \times C_{i}
$$

当 $P_{n}=0$ 时, $C_{i}$ 即为光合作用的 $\mathrm{CO}_{2}$ 补偿点 $\Gamma$ 。这里 $R_{p}$ 为光下呼吸速率, $C E$ 为羧化效率。由 于光下暗呼吸很小, 可以近似将光下叶片向无 $\mathrm{CO}_{2}$ 的空气中释放 $\mathrm{CO}_{2}$ 的速率看作光呼吸速率 (蔡时青 和许大全, 2000)。

\subsubsection{UV-B 吸收物质含量的测定}

取测定完净光合速率的成熟叶片, 在不同叶片 上取直径 $0.7 \mathrm{~cm}$ 的叶圆片共 30 片, 分 3 组, 分别浸 入含 $40 \mathrm{ml} 79 \%$ 酸化甲醇的样品瓶中, 盖紧密封, 避 光低温 10 d。测定方法见 Caldwell(1968)。结果以 $40 \mathrm{ml}$ 酸化甲醇提取液中, 每单位面积叶片在 250 $350 \mathrm{~nm}$ 范围内吸收曲线的面积表示, 即 $\mathrm{A} \cdot \mathrm{cm}^{-2} \cdot 40$ $\mathrm{ml}^{-1}$ 。

\subsection{3 叶绿素和类胡萝卜素含量的测定}

取测定完净光合速率的成熟叶片, 在不同叶片 上取直径 $0.7 \mathrm{~cm}$ 的叶圆片共 30 片, 分 3 组, 分别浸 入 $10 \mathrm{ml} 80 \%$ 丙酮的提取液中, 盖紧样品瓶并密封, 避光低温浸提 $48 \mathrm{~h}$ 至叶圆片无色。叶绿素含量的 测定与计算见 Arnon (1949)法。类胡萝卜素含量的 计算见朱广廉(1990)。

\section{3 .4 统计分析}

\section{以上数据采用 SPSS 软件做统计分析。}

\section{2 结果和分析}

\section{1 不同植物光合作用的光响应比较}

采用 LI-6400 所配红蓝光源进行光合作用的光 响应测定。结果表明, 唐古特大黄叶片的 $P_{n}$ 在 $P F D$ 为 $2000 \mu \mathrm{mol}$ photons $\cdot \mathrm{m}^{-2} \cdot \mathrm{s}^{-1}$ 以内均未达到完 全饱和 (图 1), 说明其潜在的光合能力很大; 山莨宕 和菘蓝植物的光响应曲线相似, 两者的 $P_{n}$ 均在 $P F D$ 为 $1000 \mu \mathrm{mol}$ photons $\cdot \mathrm{m}^{-2} \cdot \mathrm{s}^{-1}$ 左右能达到基本 饱和, 随 $P F D$ 的继续增强没有发生 $P_{n}$ 的减低现象; 麻花芜叶片的 $P_{n}$ 和光合作用的饱和光强都很低, 部分原因可能是强光下叶片气孔的关闭引起了气孔 导度的下降, 从而限制了 $\mathrm{CO}_{2}$ 分子的扩散。

弱光下 $\left(0 \sim 200 \mu \mathrm{mol}\right.$ photons $\left.\cdot \mathrm{m}^{-2} \cdot \mathrm{s}^{-1}\right)$ 光合作 用的测定表明, 唐古特大黄叶片光合作用的 $A Q Y$ 明 显低于其它 3 种植物 (表 1); 山莨宕和菘蓝植物叶 片的 $A Q Y$ 较大, 但两者无明显差异。尽管 $A Q Y$ 很 低, 但唐古特大黄叶片光合作用的光补偿点 $\left(\Phi_{i}\right)$ 显 著大于其它 3 种植物。麻花艽叶片的最大净光合速
率 $\left(P_{m a x}\right)$ 显著低于其它植物, 其暗呼吸速率 $\left(R_{d}\right)$ 也 显著小于唐古特大黄和菘蓝。由于唐古特大黄叶片 光合作用在 $P F D$ 大于 $2000 \mu \mathrm{mol}$ photons $\cdot \mathrm{m}^{-2} \cdot \mathrm{s}^{-1}$ 以后依然具有一定的上升趋势, 故以 $2000 \mu \mathrm{mol}$ photons $\cdot \mathrm{m}^{-2} \cdot \mathrm{s}^{-1}$ 下的 $P_{n}$ 作为 $P_{\text {max }}$ 并于其它 3 种植物进 行比较。结果表明, 唐古特大黄叶片的 $P_{\text {max }}$ 依然显 著大于植物。统计分析表明, 低海拔植物菘蓝与高 山植物山莨宕的 $A Q Y 、 \Phi_{i} 、 R_{d}$ 和 $P_{\max }$ 均无显著差异, 两者的 $A Q Y$ 都显著高于唐古特大黄和麻花芜, 但 $P_{\text {max }}$ 界于两植物之间, 这也说明弱光下植物叶片的 $A Q Y$ 和强光下的 $P_{\text {max }}$ 之间没有一定的必然联系。

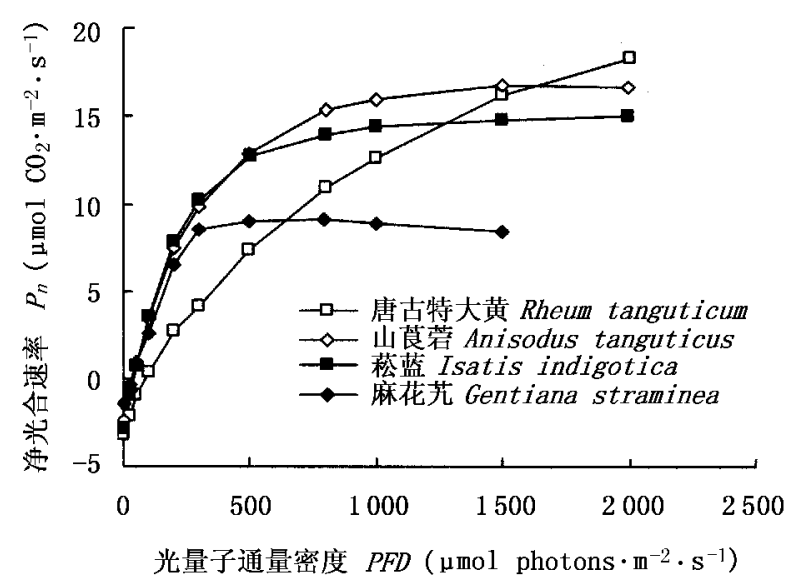

图 1 不同植物叶片净光合速率对光量子通量密度的响应 Fig.1 Response of net photosynthesis rate $\left(P_{n}\right)$ to photon flux density $(P F D)$ in the four different species leaves

2.2 不同植物的光合作用 $\mathrm{CO}_{2}$ 补偿点和光呼吸速 率比较

由图 2 可知, 叶片 $P_{n}$ 在随胞间 $\mathrm{CO}_{2}$ 浓度 $\left(C_{i}\right)$ 经

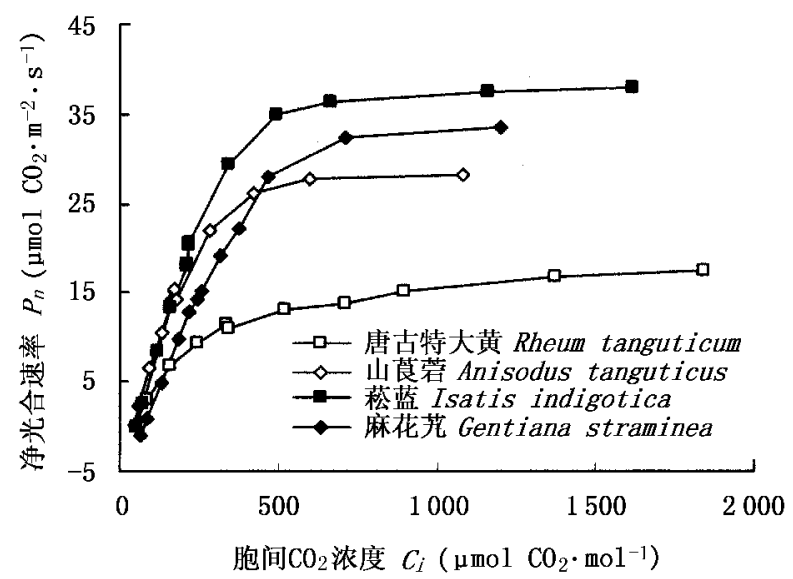

图 2 不同植物叶片净光合速率对胞间 $\mathrm{CO}_{2}$ 浓度的响应

Fig.2 Response of net photosynthesis rate $\left(P_{n}\right)$ to intercellular $\mathrm{CO}_{2}$ concentration $\left(C_{i}\right)$ in the four different species leaves 
一初始线形增加后, 紧跟着一个拐向较缓慢增长的 响应阶段。由于 4 种植物的 $P_{n}$ 随 $C_{i}$ 继续增加都变 化很小, 根据 Sage 和 Reid(1994)观点, 可以认为它们 在达到 $\mathrm{CO}_{2}$ 饱和点以后都表现为无机磷 $\left(\mathrm{P}_{\mathrm{i}}\right)$ 周转限 制的光合作用过程。

唐古特大黄叶片光合作用的 $C E$ 和 $R_{p}$ 均显著 低于其它 3 种植物 (表 2 ), 但 $\Gamma$ 界于两种高山植物 之间, 且与低海拔植物菘蓝无显著差异。山莨宕植 物的光合作用具有较高的 $C E$, 并且与其它两种高 山植物有显著差异, 但其 $\Gamma$ 明显低于其它 3 种植 物, $R_{p}$ 也与其它植物有显著差异。麻花艽植物具有 较高的 $R_{p}$ 和 $\Gamma$ 。统计分析表明, 3 种高山植物的 $C E 、 R_{p}$ 和 $\Gamma$ 均有显著差异。

2.3 叶片 UV-B 吸收物质含量和光合色素含量的
变化

紫外线-B 吸收物质 (UV-B-absorbing compounds) 为一些类黄酮物质的总称, 主要存在于叶片的表皮 层细胞中, 能有效地吸收太阳辐射光谱中 UV-B 波 段的辐射, 保护叶肉细胞中的光合机构以及生物大 分子 DNA 等免受损伤 (Beggs \& Wellmann, 1994; Fiscus \& Booker, 1995)。以单位叶片面积表示时, 4 种 植物叶片酸化甲醇的提取液中 UV-B 吸收物质的含 量依次为: 唐古特大黄 $>$ 麻花艽 $>$ 菘蓝 $>$ 山莨宕。 单位叶片面积中总叶绿素和类胡萝卜素的含量变化 有相同趋势, 依次为: 唐古特大黄 $>$ 麻花艽 $>$ 山莨宕 $>$ 菘蓝。表 3 表明, 无论 UV-B 吸收物质还是叶片 总叶绿素含量, 唐古特大黄和麻花艽都较高, 但两高 山植物间并无显著差异。

表 1 高山植物和低海拔植物的光合作用光响应参数比较

Table 1 Comparison of photosynthetic parameters between alpine and low land species

\begin{tabular}{|c|c|c|c|c|}
\hline & $\begin{array}{c}\text { 表观量子效率 } A Q Y \\
\left(\mu \mathrm{mol} \mathrm{CO} \mathrm{CO}_{2} \cdot \mu \mathrm{mol}^{-1} \text { photon }\right)\end{array}$ & $\begin{array}{c}\text { 光补偿点 } \Phi_{i} \\
\left(\mu \mathrm{mol} \text { photons } \cdot \mathrm{m}^{-2} \cdot \mathrm{s}^{-1}\right)\end{array}$ & $\begin{array}{c}\text { 暗呼吸速率 } R_{d} \\
\left(\mu \mathrm{mol} \mathrm{CO}_{2} \cdot \mathrm{m}^{-2} \cdot \mathrm{s}^{-1}\right)\end{array}$ & $\begin{array}{l}\text { 最大净光合速率 } P_{\text {max }} \\
\left(\mu \mathrm{mol} \mathrm{CO}{ }_{2} \cdot \mathrm{m}^{-2} \cdot \mathrm{s}^{-1}\right)\end{array}$ \\
\hline 唐古特大黄 Rheum tanguticum & $0.0304 \pm 0.0050^{\mathrm{a}}$ & $86.00 \pm 14.74^{\mathrm{a}}$ & $-2.88 \pm 0.46^{\mathrm{a}}$ & $20.03 \pm 3.83^{\mathrm{a}}$ \\
\hline 山莨蓉 Anisodus tanguticus & $0.0474 \pm 0.0015^{\mathrm{b}}$ & $41.31 \pm 9.89^{\mathrm{b}}$ & $-2.38 \pm 0.46^{\mathrm{ab}}$ & $15.14 \pm 0.80^{\mathrm{b}}$ \\
\hline 菘蓝 Isatis indigotica & $0.0518 \pm 0.0009^{\mathrm{b}}$ & $48.67 \pm 4.83^{b}$ & $-3.01 \pm 0.12^{\mathrm{a}}$ & $15.53 \pm 1.57^{\mathrm{b}}$ \\
\hline 麻花艽 Gentiana straminea & $0.0372 \pm 0.0056^{\mathrm{c}}$ & $48.13 \pm 14.56^{\mathrm{b}}$ & $-1.84 \pm 0.49^{b}$ & $9.15 \pm 2.23^{\mathrm{c}}$ \\
\hline
\end{tabular}

数据以平均数 \pm 标准差表示, 菘蓝和麻花艽的样本数 $n=4$, 山莨若和唐古特大黄 $n=5$ Data showed above is means $\pm S D$, for Isatis indigotica and Gentiana straminea $n=4$ and for Anisodus tanguticus and Rheum tanguticum $n=5$ 同一列上标相同字母为差异不显著 $(p<0.05)$ Within each line, values followed by the same letter are not significant difference at $p<0.05$ according to $L S D$ multiple test $A Q Y$ : Photosynthetic quantum yield $\Phi_{i}$ : Photo flux density in $P_{n}=0 \quad R_{d}$ : Dark respiratory rate $P_{\max }$ : Max net photosynthesis rate

表 2 高山植物和低海拔植物光合作用的羧化效率、光呼吸速率和 $\mathrm{CO}_{2}$ 补偿点比较

Table 2 Comparison in carboxylation efficiency $(C E)$, photorespiration rate $\left(R_{p}\right)$ and the $\mathrm{CO}_{2}$ compensation point $(\Gamma)$ between alpine and low land species

\begin{tabular}{|c|c|c|c|}
\hline & $\begin{array}{l}\text { 羧化效率 } C E \\
\left(\mu \mathrm{mol} \cdot \mu \mathrm{mol}^{-1}\right)\end{array}$ & $\begin{array}{c}\text { 光呼吸速率 } R_{p} \\
\left(\mu \mathrm{mol} \mathrm{CO}_{2} \cdot \mathrm{m}^{-2} \cdot \mathrm{s}^{-1}\right)\end{array}$ & $\begin{array}{c}\mathrm{CO}_{2} \text { 补偿点 } \Gamma \\
\left(\mu \mathrm{mol} \mathrm{CO} \mathrm{CO}_{2} \cdot \mathrm{mol}^{-1}\right)\end{array}$ \\
\hline 唐古特大黄 Rdeum tanguticum & $0.0453 \pm 0.0066^{\mathrm{a}}$ & $-2.58 \pm 0.33^{\mathrm{a}}$ & $57.30 \pm 5.69^{\mathrm{ac}}$ \\
\hline 山莨菪 Anisodus tanguticus & $0.1116 \pm 0.0026^{\mathrm{b}}$ & $-4.49 \pm 0.27^{\mathrm{b}}$ & $40.18 \pm 1.48^{\mathrm{b}}$ \\
\hline 菘蓝. Isatis indigotica & $0.1077 \pm 0.0139^{\mathrm{bc}}$ & $-6.00 \pm 0.75^{c}$ & $55.77 \pm 1.70^{c}$ \\
\hline 麻花芜 Gentiana Straminea & $0.0902 \pm 0.0119^{c}$ & $-6.45 \pm 0.66^{c}$ & $71.63 \pm 2.55^{\mathrm{d}}$ \\
\hline
\end{tabular}

数据以平均数 \pm 标准差表示, $n=3$ Data showed above is means $\pm S D, n=3$ 同一列上标相同字母为差异不显著 $(p<0.05)$ Within each line, values followed by the same letter are not significant difference at $p<0.05$ according to $L S D$ multiple test

表 3 高山植物和低海拔植物叶片中 UV-B 吸收物质、叶绿素和类胡萝卜素含量的比较

Table 3 Comparison of alpine and low land species in concentrations of UV-B-absorbing compounds, chlorophyll and carotenoid

\begin{tabular}{lccc}
\hline & $\begin{array}{c}\text { UV-B 吸收物质 } \\
\text { UV-B-absorbing compounds } \\
\left(\mathrm{A} \cdot \mathrm{cm}^{-2} \cdot 40 \mathrm{ml}^{-1}\right)\end{array}$ & $\begin{array}{c}\text { 叶绿素 } \\
\text { Chlorophyll }\left(\mathrm{mg}^{\bullet} \mathrm{cm}^{-2}\right)\end{array}$ & $\begin{array}{c}\text { 类胡萝卜素 } \\
\text { Carotenoid }\left(\mathrm{mg}^{\bullet} \mathrm{cm}^{-2}\right)\end{array}$ \\
\hline 唐古特大黄 Rdeum tanguticum & $41.6831 \pm 5.7752^{\mathrm{ad}}$ & $0.1338 \pm 0.0136^{\mathrm{ad}}$ & $0.0652 \pm 0.0055^{\mathrm{a}}$ \\
山莨菪 Anisodus tanguticus & $15.4925 \pm 2.5225^{\mathrm{b}}$ & $0.0838 \pm 0.0089^{\mathrm{b}}$ & $0.0404 \pm 0.0040^{\mathrm{b}}$ \\
菘蓝 Isatis indigotica & $25.0854 \pm 2.3132^{\mathrm{c}}$ & $0.0417 \pm 0.0117^{\mathrm{c}}$ & $0.0177 \pm 0.0049^{\mathrm{c}}$ \\
麻花芜 Gentiana Straminea & $37.2295 \pm 6.9890^{\mathrm{d}}$ & $0.1294 \pm 0.0126^{\mathrm{d}}$ & $0.0576 \pm 0.0037^{\mathrm{d}}$ \\
\hline
\end{tabular}

数据以平均数 \pm 标准差表示, $n=5$ Data showed above is means $\pm S D, n=5$ 同一列上标相同字母为差异不显著 $(p<0.05)$ Within each line, values followed by the same letter are not significant difference at $p<0.05$ according to $L S D$ multiple test 


\section{3 讨 论}

青藏高原药用植物在我国资源植物中占有相当 的比例, 尽管目前开发利用的只是其中一些名贵种 类, 但由于长期滥挖乱采, 不仅破坏了当地脆弱的自 然生态系统, 而且使一些物种处于濒危的边缘。因 此, 采用人工栽培的途径开发药用植物, 是保护生物 学的一个重要途径。

3 种高山药用植物中除麻花艽植物的生长海拔 较高, 为高寒草甸的主要伴随植物外, 唐古特大黄和 山莨宕的海拔分布下限与西宁地区相近, 且都要求 土质松软、水分供应充足的生长环境。因此在西宁 地区进行人工栽培具有得天独厚的条件。该文采用 青藏高原 3 种高山药用植物并与低海拔药用植物菘 蓝进行比较, 探讨了高山药用植物对高原环境的适 应性, 同时为合理栽培高山药用植物提供科学理论 依据。

高山地区植物的生存环境相对恶劣, 能在此极 端环境下生存繁衍的植物都具有一些形态解剖和生 理生化等方面的进化适应方式 (卢存福等, 2000; 吴 学明, 1997; Goldstein et al., 1999)。高山植物的光 合特性反映了植物对高原特殊自然环境条件的响应 和适应。响应反映了植物生理功能对短期环境变化 的反应; 适应性主要指在长期的特定环境中植物所 形成的形态、结构以及生理功能的变化。不同的高 山植物移栽至相同的自然环境条件后, 对外界环境 因子的响应和适应也不完全相同 (Rawat \& Purohit, 1991)。但同一种高山植物培养在不同温度和日温 差的环境条件下却表现出几乎相同的最大光合速率 和光合适温, 仅低温生长环境中的高山植物具有较 高的暗呼吸速率 (Goldstein et al., 1999)。Westbeek 等(1999)比较了高山、亚高山和低海拔起源的 7 种 早熟禾属植物的光合作用, 发现以单位叶片面积表 示时, 高海拔地区来源的植物的最大光合速率大于 低海拔地区, 羧化能力也一样。但这并不意味着高 山植物总是比低海拔植物具有较高的光合速率和羧 化能力, 不同科属的植物间往往也会有较大的差异 (Larcher, 1980)。

青藏高原的高山植物由于受低温低气压等不利 环境因素的影响, 加之强辐射下植物时常存在一定 程度的光合作用光抑制现象, 因此光合作用的量子 效率偏低( 郭连旺等, 1995)。本文的研究结果也表 明, 3 种高山植物的 $A Q Y$ 都小于低海拔植物菘蓝 (表 1 )。唐古特大黄在弱光下的 $A Q Y$ 最低, 但 $\Phi_{i}$ 很高,
且在全日照的自然光辐射强度范围内依然没有达到 光合作用的光饱和, 这一特性与麻花芜具有的较低 $A Q Y$ 和很低的 $P_{\text {max }}$ 完全相反, 表明叶片 $A Q Y$ 并不决 定 $P_{\text {max }}$ 的大小 (许大全, 2002)。唐古特大黄叶片的 $C E$ 和 $R_{p}$ 都很低, 说明叶片中活化的 Rubisco 酶量较 少, 光合作用的羧化限制程度大。自然条件下栽培 的唐古特大黄叶片的 $P_{n}$ 随 $P F D$ 的增强而不断增 大, 光合作用的不断提高反映了植物对强太阳辐射 的一种适应方式, 这显然与叶片总叶绿素明显较高 有关。同时叶片表皮细胞中含量丰富的 UV-B 吸收 物质能吸收强太阳辐射中的 UV-B 辐射部分, 使叶 肉细胞中叶绿体等器官的功能免遭伤害, 为光合机 构的正常运行提供了内部保护“屏障”(师生波等, 1999)。

与唐古特大黄对强辐射的适应方式相反, 麻花 芜叶片的 $P_{n}$ 和光合作用的饱和光强都很低, 暗呼 吸速率也很低。多次实验证明, 麻花芜叶片的 $P_{n}$ 对 $P F D$ 的响应中, 当 $P F D$ 大于光合作用的饱和光 强以后, 气孔导度常有降低趋势, 而此时 $C_{i}$ 略有降 低, 可以认为在通常光强下叶片气孔导度的降低是 限制净光合速率的一个主要原因。

山莨宕与菘蓝的光合特性在很多方面具有相似 性。相比而言, 山莨宕的光呼吸速率 $R_{p}$ 和 $\mathrm{CO}_{2}$ 补 偿点 $\Gamma$ 较低。原产地在低海拔的药用植物菘蓝, 其 叶绿素和类胡萝卜素的含量都明显低于 3 种高山植 物, 但其净光合速率在光响应和 $\mathrm{CO}_{2}$ 响应中均不低。 此结果与 Westbeek 等(1999)对 7 种早熟禾属植物的 比较研究相反, 可能与低海拔植物菘蓝具有较高的 $A Q Y$ 和 $C E$ 有关。将以叶片面积表示的 $P_{n}$ 换算为 以叶绿素表示时, 可以看出表 1 中最大净光合速率 $P_{\text {max }}$ 的排序变为菘蓝 $>$ 山莨宕 $>$ 唐古特大黄 $>$ 麻花 芜。其净光合速率依次为: $(0.0372 \pm 0.0037)$ 、 $(0.0182 \pm 0.0011) 、(0.0150 \pm 0.0029) 、(0.0071 \pm$ $0.0017) \mu \mathrm{mol} \mathrm{CO}_{2} \cdot \mathrm{mg}^{-1} \mathrm{Chl} \cdot \mathrm{s}^{-1}$, 除山莨宕和唐古特 大黄之间无显著差异外, 其余相互间均存在显著差 异 $(p<0.05)$ 。同样表明, 在通常大气 $\mathrm{CO}_{2}$ 浓度范 围和温度下, 高山植物的 $P_{\text {max }}$ 并不一定大于低海拔 起源的植物。

植物光合作用的 $C_{i}$ 响应在一初始线形增加后, 紧跟着一个拐向较缓慢增长的响应阶段, 表明光合 机构由 Rubisco 限制转变为依赖类囊体的 RuBP 再 生的限制。由于 RuBP 再生依赖于同化力 ATP 和 $\mathrm{NADPH}$ 的形成, 而同化力的形成又依赖于光合电子 传递和与其偶联的光合磷酸化, 所以 $\mathrm{RuBP}$ 再生限 
制在一定程度上反映了光合电子传递和光合磷酸化 及其前面的光化学反应状况。

若植物光合作用的 $C_{i}$ 响应在一初始线形增加 后, 很快降低了对 $C_{i}$ 的敏感性, 即增加 $C_{i}$ 再不能促 进和影响 $P_{n}$, 则表现为光合作用的 $\mathrm{P}_{\mathrm{i}}$ 限制过程 ( 许 大全和沈允钢, 2001)。Pi 是植物光合作用不可缺少 的元素, 在通常光合作用过程中 Pi 能被循环使用。 在光反应过程中 $\mathrm{Pi}$ 参与形成 $\mathrm{ATP}$, 而当 $\mathrm{ATP}$ 被用于 碳同化时 $\mathrm{Pi}$ 被结合形成磷酸丙糖, 结合在磷酸丙糖 中的 Pi 随淀粉和蔗糖的进一步合成而释放出来, 加 入到 Pi 的循环利用。如果磷酸丙糖被用于合成淀 粉和蔗糖的速率低于它生成的速率, Pi 再生释放就 会过于缓慢, 从而对光合作用过程形成限制。可以 推断图 2 中 4 种植物的光合作用主要为 $\mathrm{Pi}$ 再生的 限制。Sage 和 Reid (1994) 指出, 假如 Pi 的再生能力 降低很多, Rubisco 限制将在 $\mathrm{CO}_{2}$ 饱和点直接变为 $\mathrm{Pi}$ 再生限制的光合作用, 在这种情况下 $\mathrm{C}_{3}$ 植物光合作 用的 $C_{i}$ 响应可能类似于 $\mathrm{C}_{4}$ 植物。图 2 中唐古特大 黄光合作用的 $C_{i}$ 响应很低, 可能是因为较低的 $R_{p}$ 水平导致了较大的 $\mathrm{Pi}$ 再生周转的限制。唐古特大 黄属于 $\mathrm{C}_{3}$ 植物, 但叶片的 $R_{p}$ 相对较低, 可能与叶片 中活化的 Rubisco 羧化/加氧酶的量较低有关, 也是 导致 $P_{n}$ 对光强的响应与典型 $\mathrm{C}_{4}$ 植物类似的一个原 因。光呼吸在植物气体代谢中的意义目前尚不能完 全确定, 通常认为, 在干旱和高辐射期间, 气孔关闭, $\mathrm{CO}_{2}$ 不能进入叶肉细胞会导致光抑制, 此时光呼吸 释放 $\mathrm{CO}_{2}$, 消耗多余能量, 对光合器官起保护作用。 许大全和沈允钢 (2001) 认为, $C_{3}$ 植物的光呼吸可能 是耗散过剩光能, 保护光合机构免于强光破坏的一 个途径; 同时, 光呼吸途径在消耗多余能量的同时, 能释放被 PGA 结合的 Pi 元素, 缓解由于 $\mathrm{Pi}$ 暂时亏 缺而引起的对电子传递和光合磷酸化过程的限制。 图 2 中菘蓝和山莨宕的 $R_{p}$ 较高, 所以饱和 $\mathrm{CO}_{2}$ 时的 $P_{n}$ 也较高, 表明 $\mathrm{Pi}$ 亏缺对电子传递和光合磷酸化 过程的限制也相对较小。

唐古特大黄和麻花艽为典型青藏高原的高山植 物, 两者都有较高的叶绿素和类胡萝卜素含量, UV$\mathrm{B}$ 吸收物质的含量也很高, 但两种植物的光响应特 性差异很大。唐古特大黄的 $P_{n}$ 随 PFD 的增强能不 断升高, 在全日照最大光辐射下也未能饱和; 麻花芜 却在很低光强, 似乎在全日照光辐射的 $1 / 4$ 时即已 经达到了饱和, $P F D$ 进一步增强甚至能引起 $P_{n}$ 的 减低。可见唐古特大黄对 $P F D$ 的响应是通过 $P_{n}$ 的 不断增强而积极适应强辐射的, 麻花艽似乎以较高
的光呼吸等避免强辐射的伤害。

$$
\text { 参考 文 献 }
$$

Arnon DI ( 1949 ). Copper enzymes in isolated chloroplasts: polyphenoloxidase in Beta vulgaris. Plant Physiology, 24, 1 15.

Beggs CG, Wellmann E (1994). Photocontrol of flavonoid biosynthesis. In: Kendrick RE, Kronenberg GHM eds. Photomorphogenesis in Plants Vol. 2. Kluwer Academic, Dordrecht, 733 -750 .

Ben GY (贲桂英), Han F (韩发), Shi SB (师生波) (1993). Studies of leaf conductance, transpiration and water potential of plants in alpine Kobresia humilis Meadow. Acta Ecologica Sinica (生态学报), 13, 369 - 372. (in Chinese with English abstract)

Ben GY, Lu CF, Han F, Shi SB (1992). Characteristic of the photosynthesis in alpine plants on Qinghai plateau. In: Murata N ed. Research in Photosynthesis Volume IV. Kluwer Academic Publishers, $173-176$.

Cai SQ (蔡时青), Xu DQ (许大全) (2000). Relationship between the $\mathrm{CO}_{2}$ compensation point and photorespiration in soybean leaves. Acta Phytophysiologica Sinica (植物生理学报), 26, 545 - 550. (in Chinese with English abstract)

Caldwell MM (1968). Solar ultraviolet radiation as an ecological factor for alpine plants. Ecological Monographs, 38, 243- 267.

Fiscus EL, Booker FL (1995). Is increased UV-B a threat to crop photosynthesis and productivity? Photosynthesis Research, 43, 81 -92 .

Goldstein G, Melcher P, Heraux J, Drake DR, Giambelluca TW (1999). Photosynthetic gas exchange and temperature-induced damage in seedlings of the tropical alpine species Argyroxiphium sandwicense. Oecologia (Historical Archive), 106, 298 - 307.

Guo LW (郭连旺), Shen YK (沈允钢), Xu DQ (许大全), Zhang SY (张树源), Wu H (武海), Wu S (吴姝) (1995). Characteristic and photoinhibition of photosynthesis in some alpine meadow plants. In: Northwest Institute of Plateau Biology, Chinese Academy of Sciences (中国科学院西北高原生物研究 所) ed. Alpine Meadow Ecosystem Fasc. 4 (高寒草甸生态系 统). Science Press, Beijing, 65-72. (in Chinese with English abstract)

Larcher W (1980) . Physiological Plant Ecology 2nd edn. SpringerVerlag, Berlin, Heideberg, New York.

Lu CF (卢存福), Ben GY (贲桂英), Han F (韩发), Shi SB (师生波) (1995). A comparison studies of photosynthetic response of Kobresia humilis to different environment factors. Acta Phytoecologica Sinica (植物生态学报), 19, 72-78. (in Chinese with English abstract)

Lu CF (卢存福), Jian LC (简令成), Ben GY (贲桂英) (2000). Photosynthesis in alpine plant Lagotis brevitude and its response to freeing stress. Chinese Bulletin of Botany (植物学通 报), 17, 559-564. (in Chinese with English abstract) 
Rawat AS, Purohit AN (1991). $\mathrm{CO}_{2}$ and water vapour exchange in four alpine herbs at two altitudes and under varying light and temperature conditions. Photosynthesis Research ( Historical Archive), 28, 99 - 108 .

Sage RF, Reid CD (1994). Photosynthetic response mechanisms to environmental change in $\mathrm{C}_{3}$ plants. In: Wilkinson RE ed. Plant Environment Interactions. Marcel Dekker, New York. 413 497.

Shi SB (师生波), Han F (韩发), Li HY (李红彦) (2001). Midday depression of photosynthesis of Gentiana straminea and Saussurea superba in alpine Kobresia humilis meadow. Acta Phytophysiologica Sinica (植物生理学报), 27, 123 - 128.（in Chinese with English abstract)

Shi SB (师生波), Ben GY (贲桂英), Han F (韩发) (1999).

Analysis of the solar UV-B radiation and plant UV-B-absorbing compounds in different regions. Acta Phytoecologica Sinica (植 物生态学报), 23,529-535. (in Chinese with English abstract)

Westbeek MHM, Pons TL, Cambridge ML, Atkin OK (1999). Analysis of differences in photosynthetic nitrogen use efficiency of alpine and lowland Poa species. Oecologia, 120, 19-26.

Wu XM (吴学明) (1997). The analysis of ultrastructure of photo- synthetic membrane on Cremanthodium discoideum and Aconitum tangutcum in alpine plant. Acta Botanica Boreali-Occidentalia Sinca (西北植物学报), 17, 98 - 102. (in Chinese with English abstract)

Xu DQ (许大全), Shen YG (沈允钢) (2001). Limiting factors in photosynthesis. In: Yu SW (余叔文), Tang ZC (汤章城) eds. Plant Physiology and Plant Molecular Biology (植物生理 和植物分子生物学) 2nd edn. Science Press, Beijing, 262 276. (in Chinese)

Xu DQ (许大全) (2002). Photosynthetic Efficiency (光合作用效 率). Shanghai Scientific and Technical Publishers, Shanghai. (in Chinese)

Zhang SY (张树源), Wu H (武海), Han F (韩发) (1995). The physiological ecology studies of plants in Qinghai plateau. IV. The net photosynthetic rate of plants in different altitude. In: Northwest Institute of Plateau Biology, Chinese Academy of Sciences (中国科学院西北高原生物研究所) ed. Alpine Meadow Ecosystem Fasc. 4(高寒草甸生态系统), Science Press, Beijing, 53-58. (in Chinese with English abstract)

Zhu GL (朱广廉) (1990). The Plant Physiological Experiment (植物生理学实验). Peking University Press, Beijing, 51 54. (in Chinese) 